\title{
Monstrilloida (Crustacea: Copepoda) from the Beagle Channel, South America
}

\author{
Eduardo Suárez-Morales ${ }^{1}$, Fernando C. Ramírez ${ }^{2}$, Carla Derisio ${ }^{3}$ \\ ${ }^{1}$ El Colegio de la Frontera Sur (ECOSUR), Unidad Chetumal, P.O. Box 424, Chetumal, Quintana Roo 77014, \\ Mexico,esuarez@ecosur.mx \\ ${ }^{2}$ Instituto Nacional de Investigación y Desarrollo Pesquero (INIDEP), P.O. Box 175, \\ Mar del Plata, Argentina \\ ${ }^{3}$ Consejo Nacional de Investigaciones Científicas y Técnicas (CONICET), Argentina. Laboratorio de Zooplancton, \\ INIDEP, Mar del Plata, Argentina
}

Key words: associated Copepoda, marine zooplankton, Southern Ocean, taxonomy

\begin{abstract}
Monstrilloid copepods were collected during zooplankton surveys in the Beagle Channel at the southernmost end of South America. These specimens represent two species of Monstrillopsis, one of them undescribed, and one new species of Monstrilla. Monstrillopsis igniterra $\mathrm{n}$. sp. is related to forms of the M.dubia species group, and particularly to $M$. ferrarii and M. chilensis. It differs from these species in the relative length of the antennules, the shape and relative size of the genital double and anal somites, details of the antennular armature, and the possession of a short inner caudal seta. The other species of Monstrillopsis, M. chilensis, was previously known only from the Southeast $\mathrm{Pa}-$ cific off Chile, and was originally described from female specimens only. Male individuals found in the Beagle Channel are described and assigned herein to this species. These are the first records of Monstrillopsis from high latitudes of South America. The new species Monstrilla patagonica $\mathrm{n}$.sp. is represented by males. It is characterized by the structure and relative size of the genital lappets, details of the antennular structure, armature, relative size and the number (6) of caudal setae. It belongs to a small group of species with highly modified, pectinate male antennules. A female specimen identified as $M$. helgolandica 35 years ago from southern Argentina is tentatively reidentified as the female of this new species, based on its differences from $M$. helgolandica and the rarity of this species group in the region.
\end{abstract}

\section{Contents}

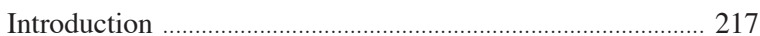

Material and methods ............................................................ 218

Results and conclusions ………………………………......... 218

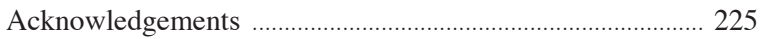

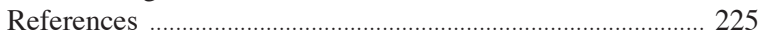

\section{Introduction}

Monstrilloid copepods are one of the eleven orders of Copepoda currently recognized (Huys and Boxshall,
1991; Ho et al., 2003). Huys et al. (2007) found that this group has strong links with the Siphonostomatoida and proposed to accommodate the Monstrilloida within the Siphonostomatoida. Monstrilloids are protelean parasites of benthic polychaetes and mollusks. Most postnaupliar and preadult stages are endoparasitic except for a brief free-swimming instar preceding the final molt. Adults are free-living forms and they are occasionally captured by plankton nets in surveys of coastal-neritic zooplankton at all latitudes (Davis and Green, 1974; Suárez-Morales, 2001, 2005; SuárezMorales and Dias, 2001; Suárez-Morales and Ivanenko, 2004). The order currently contains over 100 nominal species arranged in four genera: Monstrilla Dana 1849, Monstrillopsis Sars 1921, Cymbasoma Thompson 1888, and Maemonstrilla Grygier and Ohtsuka 2008 (Grygier 1994; Suárez-Morales and Gasca, 2004; SuárezMorales et al., 2006; Grygier and Ohtsuka, 2008).

Because of their rarity in the plankton and their taxonomic complexity, there are large geographic areas in which the monstrilloid copepod fauna remains unknown. One of these is the Southern Ocean, including the Antarctic Convergence. In the Americas there are few records of Monstrilloida from high latitudes of the Southern hemisphere (i.e. Ramírez, 1971; Marín and Antezana, 1985; Dias, 2005; Suárez-Morales et al., 2006; Dias and Bonecker, 2007a, b; Biancalana et al., 2007; Hoffmeyer and Barría de Cao, 2007), and only two species have been hitherto reported from Subantarctic waters (Razouls, 1996).

The Beagle Channel is a narrow (ca. $5 \mathrm{~km}$ ) and relatively long $(240 \mathrm{~km})$ strait separating the islands of the Tierra del Fuego archipelago from the mainland at the southernmost end (54 53'S) of South America (Bujalesky et al., 2004). Depth varies in different sectors, 
from 30 to $300 \mathrm{~m}$, but coastal environments and embayments are predominant. The zooplankton of the Beagle Channel has been studied recently to obtain a basic set of information on the bio-ecological aspects of this community (Fernández-Severini and Hoffmeyer, 2005). The planktic copepods have long been studied in the South Atlantic but monstrilloids were not included (Bradford-Grieve et al., 1999). The only previous records of monstrilloids in the Beagle Channel are by Biancalana et al. (2007), who reported Cymbasoma sp. and Monstrilla helgolandica Claus, 1863. As part of a recent survey of the marine fauna of the Beagle Channel, zooplankton samples were collected from several areas; monstrilloid copepods were found only at Bahia Brown (Fig. 1). These specimens represent two species of Monstrillopsis, one of them undescribed, and one new species of Monstrilla. Both new species and the male of Monstrillopsis chilensis Suárez-Morales, BelloSmith and Palma, 2006 are described following the standards for monstrilloid copepods (Grygier and Ohtsuka, 1995). Comments on the geographic distribution of the genus Monstrillopsis are also provided.

\section{Material and methods}

Zooplankton samples were collected from the Bahia Brown, in the Beagle Channel, at two sampling stations that were visited during March and June, 2006 (Fig. 1).

Collections were made with a plankton net $(0.1 \mathrm{~mm}$ mesh-size) that was hauled obliquely in the surface layer $(0-20 \mathrm{~m})$, during daytime. Samples were fixed and preserved in a buffered solution of formalin and then transferred to $70 \%$ ethanol. Selected specimens were prepared for taxonomic analysis through light staining with methylene blue, or through the dissection of appendages in glycerine. Drawings were prepared
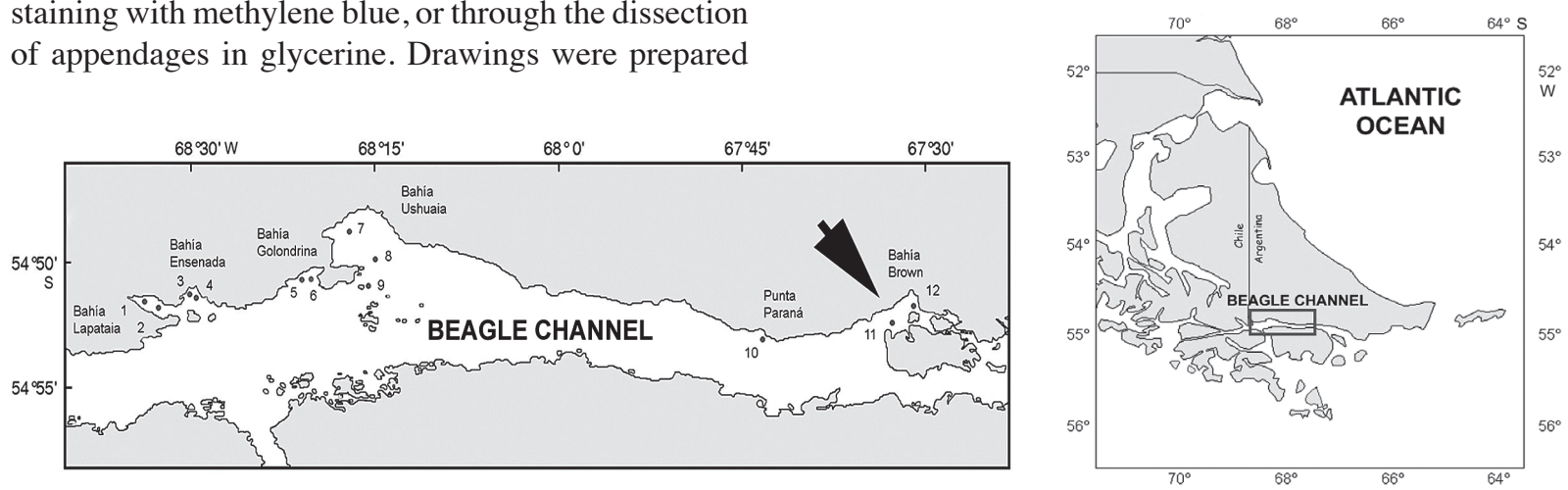

Fig. 1. General location of the Beagle Channel at the southernmost end of South America, with the sampling area, Bahia Brown (arrow). with a camera lucida and an Olympus CR31 microscope. Type specimens were deposited in the collection of Zooplankton held at El Colegio de la Frontera Sur (ECO-CHZ), in Chetumal, Mexico. Other specimens and the original plankton samples are held at INIDEP (Instituto Nacional de Investigación y Desarrollo Pesquero), Mar del Plata, Argentina.

\section{Results and conclusions}

Monstrillopsis igniterra $\mathrm{n} . \mathrm{sp}$.

Material examined. Holotype: adult female from Bahia Brown, Beagle Channel (54 53'S, $\left.67^{\circ} 29^{\prime} \mathrm{W}\right)$, Argentina, South America, undissected, ethanol-preserved. Date of collection: March 2006. Plankton sample deposited in the Collection of Zooplankton at El Colegio de la Frontera Sur (ECOSUR), in Chetumal, Mexico (ECO-CHZ-03583). Paratypes: one adult female from same area and date, undissected, deposited at INIDEP, Mar del Plata, Argentina.

Adult female. Total body length of holotype $1.18 \mathrm{~mm}$, measured from anterior end of cephalothorax to posterior end of anal somite (see Fig. 2). Paratypes $1.64 \mathrm{~mm}$ and $1.92 \mathrm{~mm}$ long. Cephalothorax $0.72 \mathrm{~mm}$ long in holotype, $0.65 \mathrm{~mm}$ and $0.68 \mathrm{~mm}$ in paratypes, representing up to $61.3 \%$ of total body length. Oral papilla slightly protuberant, located less than $21 \%$ of way back along ventral surface of cephalothorax. Pair of ocelli present, lateral pigment cups well developed, separated by half length of eye diameter, moderately pigmented; ventral cup slightly larger than lateral cups. Small patch of cuticular ridges on 'forehead'. Widebased, low conical process on ventral surface protruding between bases of antennules. Single pair of relatively large, mammiliform cuticular processes on anterior ventral surface between antennule bases and oral papilla; pair of nipple-like processes posterior to mammiliform processes surrounded by small field of faint transverse wrinkles.

Antennule length $0.25-0.28 \mathrm{~mm}$, equal to $23 \%$ of total body length and $44 \%$ of cephalothorax length. As usual in females of Monstrillopsis, antennules four-segmented, armed with 0-I; 1-V; 

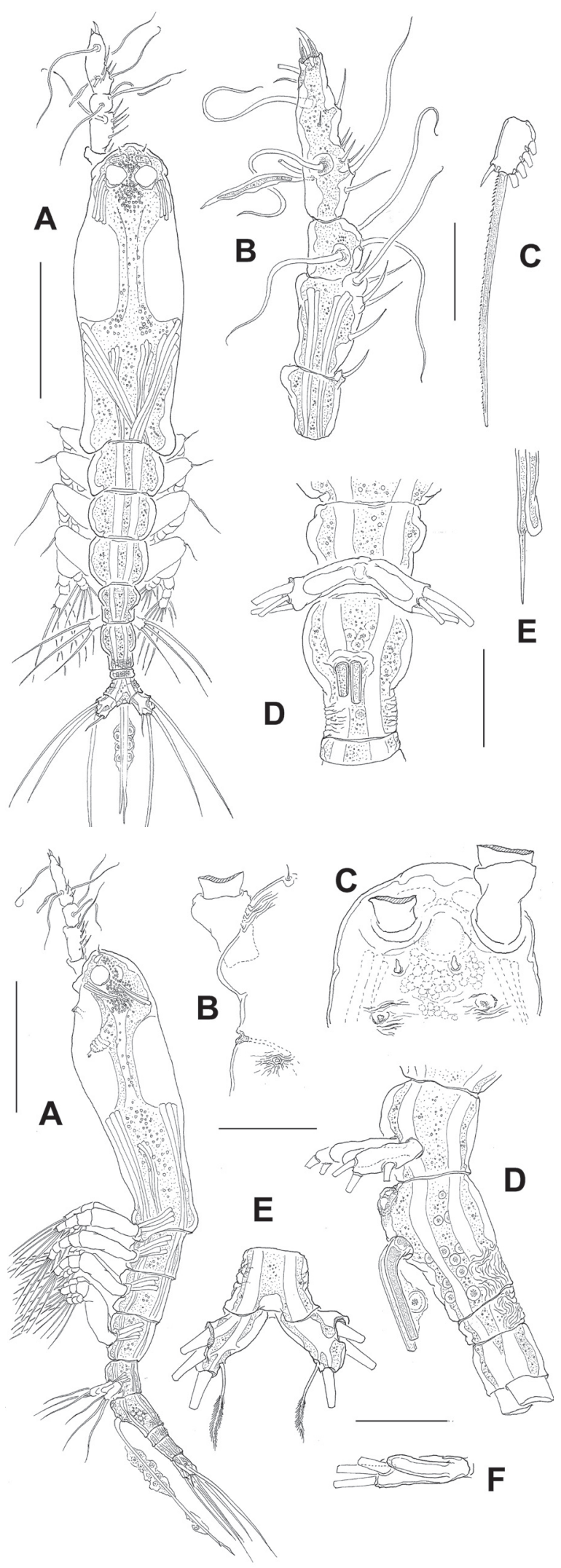

Fig. 2. Monstrillopsis igniterra, n. sp., adult female holotype from Bahia Brown, Beagle Channel.

Top panel: A) habitus, dorsal; B) right antennule, dorsal; C) distal expodal segment of second swimming leg; D) fifth legs and genital somite, ventral, ovigerous spines cut short; E, tips of ovigerous spines, ventral. Scale bars $=300 \mu \mathrm{m}$ in A and $50 \mu \mathrm{m}$ otherwise.

Bottom panel: A) habitus, lateral; B) cephalic area, lateral, showing ventral process (arrowed) and cuticular ornamentation; C) cephalic area, ventral, showing paired cuticular protuberances and ornamentation; D) urosome, lateral view, showing fifth legs and features of genital double somite, with caudal rami cut short; E) anal somite and caudal rami, dorsal. Scale bars $=300$ $\mu \mathrm{m}$ in $\mathrm{A}$ and $50 \mu \mathrm{m}$ otherwise.

2-I; 6-VIII setae (Arabic numerals) and spines (Roman numerals), plus one aesthetasc. Some elements broken off in each specimen; armature completed by adding elements present in any specimen. In terms of pattern described by Grygier and Ohtsuka (1995) for female monstrilloid antennular armature, element 1 present on first segment; elements $2 \mathrm{~d}_{1}, 2 \mathrm{~d}_{2}, 2 \mathrm{v}_{1}, 2 \mathrm{v}_{2}, 2 \mathrm{v}_{3}$, and IId on second segment. Third segment with elements 3 , IIId, and IIIv; element 3 unusually long and slender, setiform. Segment four bearing normally-developed elements $4 \mathrm{v}_{1}, 4 \mathrm{~d}_{1,2}$, and $4 \mathrm{v}_{2-3}$ as well as setae IVd, IVv, Vd, Vv, and Vm, and also element 5 . Subterminal elements $b_{1-2}$ present, remaining elements $b_{3-6}$ not observed Aesthetasc 4aes well developed, on ventral surface; terminal elements $6_{1}$ and $6_{2}$ present.

First pedigerous somite incorporated into cephalothorax; this and succeeding three free pedigerous somites each bearing pair of biramous swimming legs. Pedigerous somites 2-4 together accounting for $26 \%$ of total body length (holotype) in dorsal view. Swimming legs 1-4 slightly increasing in size posteriorly. Intercoxal sclerites of legs 1-4 rectangular, without ornamentation on surface or along distal margin. Basis of these legs articulating with large, rectangular coxa along diagonal line. Basis with hairlike lateral seta on legs 1-4; on leg 3 , this seta about four times longer and slightly thicker than on other legs, lightly setulated along distal half. Endopodites and exopodites of swimming legs 1-4 triarticulated. Ramus setae all biserially plumose except spiniform outer seta on exopod 1 and 3 , and inner seta of first exopodal segment, these latter being short, smooth. Also, outermost apical exopodal setae ('spine') of swimming legs 1-4 with inner margin naked, outer margin lightly spinulose to tip.

Armature formula of swimming legs are: leg $1-$ basis 1-0, endopodite $0-1 ; 0-1 ; 1,2,2$ and exopodite $\mathrm{I}-1 ; 0-1 ; \mathrm{I}, 2,2$ and legs $2-4-$ basis $1-0$, endopodite $0-1 ; 0-1 ; 1,2,2$ and exopodite I-1;0$1 ; \mathrm{I}, 1,2,2$.

Fifth legs medially conjoined at base, unsegmented, each consisting of relatively large outer (exopodal) lobe and inner (endopodal) digitiform lobe. Endopodal lobe relatively short, not reaching distal margin of exopodal lobe. Three long exopodal setae present, outermost two being longest, reaching about midlength of anal somite in dorsal view; third, innermost seta slightly thinner and about $15 \%$ shorter than outer ones.

Urosome consisting of four somites: fifth pedigerous somite bearing fifth legs, genital double somite, free postgenital somite, and free anal somite; ratio of length of urosomites: $34: 37.6: 7.1$ : $21.3=100$. Fifth pedigerous somite widest in its expanded ante- 
rior half; somite representing about $9.5 \%$ of total body length, about as long as two postgenital somites together; dorsal and ventral surfaces smooth. Genital double somite representing $8.3 \%$ of total body length; anterior half of genital double somite with outer margins expanded laterally, expansions slightly rounded, posterior half unexpanded, with straight margins; dorsal surface of somite with field of cuticular wrinkles reaching part of lateral surface of somite. Ventral surface with rounded protuberance on anterior proximal margin. Bases of ovigerous spines on anterior half of ventral side of double somite. Ovigerous spines paired, arising separately from protuberant base visible in lateral view; spines relatively short $(0.42 \mathrm{~mm})$, about $36 \%$ of total body length and about $63 \%$ as long as cephalothorax; adhering egg clusters along spines covered by thin, gelatinous sheath; tips of spines separated from each other, one with rounded end. Preanal somite short; anal somite large, both with striations on lateral surface.

Caudal rami subrectangular, widely divergent, approximately 1.3 times longer than wide, each bearing four setae: two terminal, one outer, and one on inner margin. Former three setae long, well-developed; innermost seta distally plumose, very small, only $12 \%$ of length of longest caudal seta.

Male. Unknown.

Host. Unknown.

Etymology. The name of the new species makes reference to the geographic area in which it was collected, Tierra del Fuego (Land of Fire), by combining the Latin nouns ignis and terra, in apposition.

The female of M. igniterra $\mathrm{n}$. sp. is assigned to the genus Monstrillopsis owing to its possession of the combination of characters defined by Sars (1921) as diagnostic of females of this genus: 1) two free postgenital somites, 2) eyes fully developed, 3) 4-segmented antennules, 4) oral papilla occurring near anteriormost part of cephalothorax, 5) fifth leg bilobed, outer lobe armed with three setae and 6) caudal rami with four setae. This species belongs to the M. dubia (Scott, 1904) species group because of the general proportions of the body and the structure and armature of the fifth legs (see Suárez-Morales and Ivanenko, 2004; Suárez-Morales et al., 2006).

The female of Monstrillopsis igniterra $\mathrm{n}$. sp. differs in several respects from $M$.dubia. The latter species has relatively longer antennules (32.5\% of total body length) than the new species (24\%); both, however, share a relatively long terminal antennular segment. Monstrillopsis dubia (sensu Scott, 1904) has a short, robust genital double somite (see Scott, 1904: pl. XIV, Fig. 18) 1.2 times wider than it is long. This somite represents about $4 \%$ of the total body length and $41.6 \%$ of the urosome length, whereas the corresponding structure has a different shape and greater relative length (8.3\% of total body length) in the new species. Also, the fifth pedigerous somite is relatively smaller in $M$. dubia (sensu Scott, 1904) than in M. igniterra. As in M.dubia, in the new species the anal somite is longer than the preanal somite; however, in the former species it represents $30 \%$ of the urosomal length vs. $24.4 \%$ in $M$. igniterra. The general structure and armature of the female fifth leg is similar in the two species, but $M$. igniterra lacks the distal process on the outer lobe. The new species can be distinguished from $M$. dubioides Suárez-Morales, 2004, formerly described by Sars (1921) as M.dubia, by its size $(1.18 \mathrm{~mm} v s .3 .8 \mathrm{~mm}$ in $M$. dubioides), but mainly by the absence of a distal process on the outer lobe of the fifth leg, a character present only in M.dubia and M.dubioides (see SuárezMorales et al., 2006).

Monstrillopsis igniterra, on the other hand, is quite close morphologically to M. chilensis and M.ferrarii, Suárez-Morales and Iranenko, 2004, both belonging to the M. dubia species group (Suárez-Morales and Ivanenko, 2004; Suárez-Morales et al., 2006). The three species share a relatively long cephalothorax (over 60\% of total body length), four furcal setae, a digitiform inner lobe on the female fifth leg, an outer lobe furnished with three long setae, a distal antennular segment representing close to half the length of the antennule, and a relatively long genital double somite. The new species differs from these congeners in several respects. The relative length of the genital double somite in the new species $(8.2 \%$ of total body length, $37 \%$ of urosome length) is different from those of the other two $(7.9 \%$ and $33 \%$, respectively, in M. ferrarii, $8.4 \%$ and $39.2 \%$ in $M$. chilensis). The anal somite is relatively larger in $M$. igniterra $(21.3 \%$ of urosome length) than in $M$. ferrarii (11\%) or M. chilensis $(17.5 \%)$ and the preanal somite is shortest in M. igniterra $(7.1 \%$ of urosome vs. $23 \%$ in M ferrarii, $13.6 \%$ in $M$. chilensis) The structure of the fifth legs differs in subtle characters, the innermost seta on the outer lobe being shortest in M. chilensis (Suárez-Morales et al., 2006: fig. 4B) and relatively longer in the other two species, while the outer setae are longer in M.ferrarii (see Suárez-Morales and Ivanenko, 2004: Fig. 6A) than in the new species. The cephalic ornamentation differs among the three species; in M. ferrarii, the cephalic area is heavily ornamented on the ventral and dorsal surfaces and the species bears a characteristic set of corrugated protuberances on the head visible on dorsal view. These are absent in both $M$. chilensis and $M$. igniterra, but the former lacks the ventral conical process on the cephalic area that is a distinguishing character in the new species. Another distinguishing apomorphy of the new species is the short inner caudal seta, which is about the same length of the caudal rami 


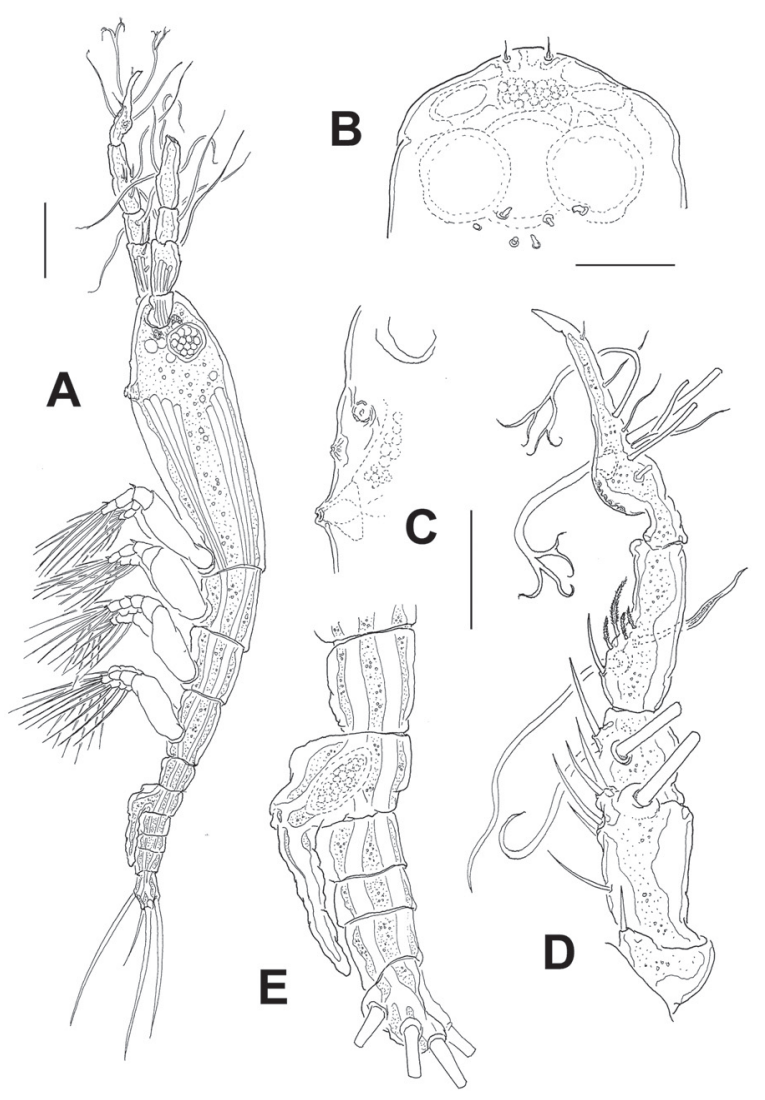

Fig. 3. Monstrillopsis chilensis, adult male from Bahia Brown, Beagle Channel.

Left panel: A) habitus, lateral; B) cephalic area, ventral, showing cuticular ornamentation; C) same, lateral; D) right antennule, dorsal view; E) urosome, lateral, showing genital lappets. Scale bars $=100 \mu \mathrm{m}$ in A and $50 \mu \mathrm{m}$ otherwise.

Right panel: A) habitus, dorsal; B) urosome, dorsal; C) same, ventral. Scale bars $=100 \mu \mathrm{m}$ in A and $50 \mu \mathrm{m}$ otherwise.

Fig. 4. As Fig. 3, adult female: A) habitus, dorsal; B) cephalic area, lateral, showing cuticular processes and ornamentation; $\mathrm{C}$ ) same, ventral view; D) left antennule, dorsal; E) urosome, lateral. Scale bars $=300 \mu \mathrm{m}$ in A and $100 \mu \mathrm{m}$ otherwise.

in the new species and 2.5 and 6.2 times as long as the rami in $M$. chilensis and $M$.ferrarii, respectively.

Monstrillopsis chilensis Suárez-Morales, Bello-Smith and Palma, 2006

Material examined. Adult female from Bahia Brown, Beagle Channel (54 $\left.{ }^{\circ} 53^{\prime} \mathrm{S}, 67^{\circ} 29^{\prime} \mathrm{W}\right)$, Argentina, collected March, 2006. Specimen mounted in glycerine, undissected, deposited in ECOCHZ-03582. Adult male from same site and date, plankton sample, undissected, ethanol-preserved; vial deposited in ECOCHZ-03584. Two adult males from same area and date, undissected. Vial deposited at INIDEP, Mar del Plata, Argentine.
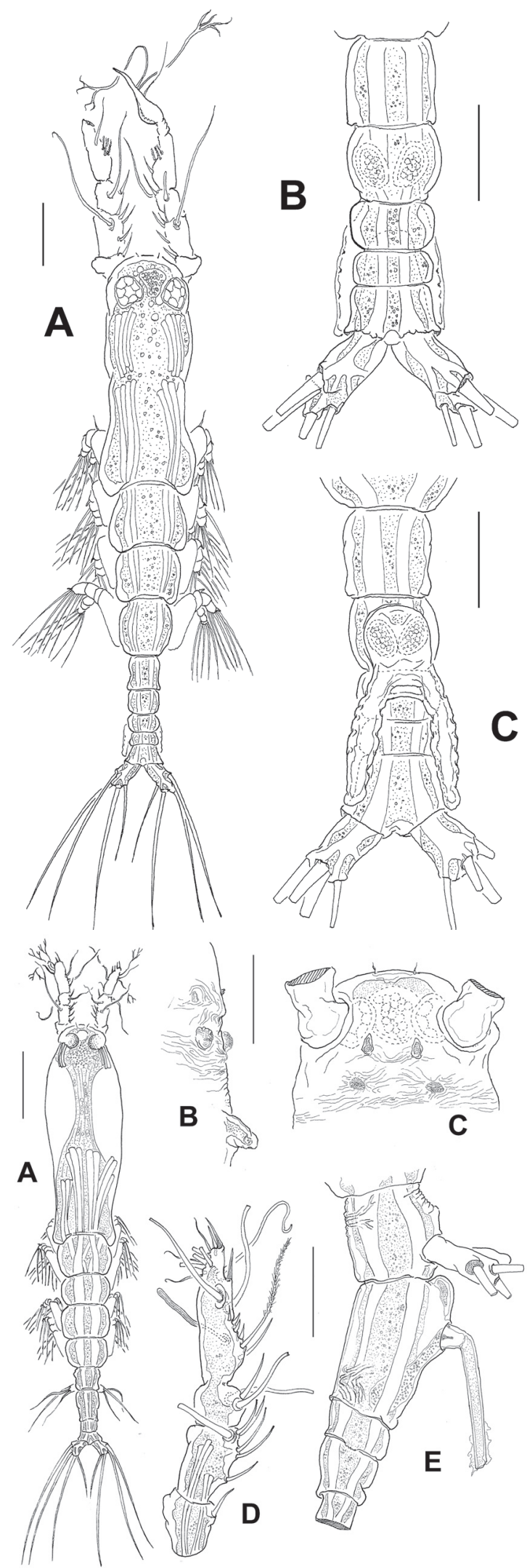
Description of male (see Fig. 3). Total body length of male 0.78 $\mathrm{mm}$. Cephalothorax $0.46 \mathrm{~mm}$ long, representing up to $45 \%$ of total body length. Oral papilla slightly protuberant, located $30 \%$ of way back along ventral surface of cephalothorax. Pair of ocelli present, pigment cups medially conjoined, separated by less than one eye diameter; ventral cup of naupliar eye about same size as lateral cups. Three pairs of small mammiliform processes on anterior ventral surface between antennule bases and oral papilla. Other ventral cuticular ornamentation including two pairs of nipple-like processes with small field of wrinkles.

Antennule length $0.43 \mathrm{~mm}$, equal to $45 \%$ of total body length and as long as cephalothorax. As usual in male monstrilloids, antennules geniculate, five-segmented, armed as: 0-I; 1-V; 1-V; 8 -I, plus two aesthetascs. In terms of pattern described by Grygier and Ohtsuka (1995) for female monstrilloid antennular armature and complemented with nomenclature by Huys et al. (2007) for elements on distal segment of males, element 1 present on first segment; elements $2 \mathrm{~d}_{1}, 2 \mathrm{~d}_{2}, 2 \mathrm{v}_{1}, 2 \mathrm{v}_{2}, 2 \mathrm{v}_{3}$, and IId on second segment. Third segment with elements 3 , IIId, and IIIv. Segment four bearing normally developed elements $4 d_{1,2}$ and $4 \mathrm{v}_{1-3}$ as well as setae IVd and IVv. Aesthetasc 4aes well developed, on ventral surface. Terminal segment armed as follows: elements 1-7 present on anterior margin, dichotomously branched elements $\mathrm{A}$ and B on posterior margin. As usual in male Monstrillopsis, terminal antennular segment modified, with inner rounded expansion ridged and distal half elongated, forming a sabre-like structure, curved distally.

Pedigerous somites 2-4 together accounting for $34.5 \%$ of total body length in dorsal view. Swimming legs 1-4 as in female. Fifth legs absent.

Urosome consisting of five somites: fifth pedigerous somite, genital somite with genital complex, two free postgenital somites, and free anal somite. Ratio of lengths of genital somite and succeeding somites: $31: 31: 16.3: 21.7=100$. Ventral surface of genital somite strongly protuberant, forming enlarged base of paired genital lappets. Lappets posteriorly directed, moderately divergent, extremely long ( $0.1 \mathrm{~mm}, 13 \%$ of body length), reaching distal margin of anal somite, outer margins of lappets roughly corrugated. Caudal rami subrectangular, divergent, approximately 1.2 times longer than wide, each ramus bearing four well-developed setae: two terminal, one outer, and one on inner margin. Innermost seta shortest, about half as long as longest caudal seta.

Distribution. This species was originally described from off the Chilean coasts in the Southeastern Pacific ( $33^{\circ} \mathrm{S}$ ) (SuárezMorales et al., 2006); its occurrence in the surveyed area at $54^{\circ} \mathrm{S}$ represents a significant southward expansion of its known geographic range and the second finding of this species.

The female specimen examined herein has the characters described by Suárez-Morales et al. (2006) from females collected off the Chilean coast, except for a relatively longer innermost seta on the outer lobe of the female fifth leg (Fig. 4A) and relatively stronger antennular elements $6_{1}$ and $6_{2}$ (Fig. 4D). Both groups of specimens share important diagnostic characters including the relative size of the caudal setae, the shape, length, and cuticular ornamentation of the genital double somite (Fig. 4E), the corrugation on the fifth pedigerous somite, the ornamentation and processes on the cephalic ventral surface (Figs. 4 B, C), the dagger-like antennular element 5 , and the relatively short inner lobe of the female fifth legs.

The male specimens collected from Bahia Brown and advanced herein as the males of $M$. chilensis are easily assignable to the genus Monstrillopsis by their possession of four caudal setae, but mainly by the presence of a modified fifth antennular segment, with an inner rounded protuberance and an attenuated, sabrelike distal half; this kind of modification occurs only in males of Monstrillopsis (see Huys and Boxshall, 1991). The specimens from the Beagle Channel are characterized by extremely long genital lappets, comparable only to those depicted by Isaac (1974) in M. sarsi Isaac 1974, but, aside from obvious differences in body proportions and shape, in the new species the lappets are not as divergent and have corrugated margins versus a smooth surface in M. sarsi.

One of the main problems related to the taxonomy of the Monstrilloida is the strong sexual dimorphism; it is difficult to match males to females because specimens of either sex are usually found randomly in plankton samples. Only a few species have been described based on both sexes. In some cases these can be linked when they are found in the same host (Gallien, 1934; McAlice, 1985; Grygier and Ohtsuka, 2008) or when some distinguishing morphological characters are present in both sexes (Suárez-Morales and Escamilla, 1997). A genetic matching may be another option but in this case, genetic analysis of the formalin-preserved specimens from the Beagle Channel was not possible. Finally, the co-occurrence in the same sampling site alone is unreliable where many species are present; these areas include coral reefs and tropical and subtropical coastal systems. However, the diversity of the group declines at high latitudes and only a few species have been recorded from polar regions (Davis and Green, 1974; Razouls, 1996; Suárez-Morales and Ivanenko, 2004).

These male specimens were linked to the female of $M$. chilensis by the resemblance of the antennular elements on segments 1-3 in both sexes, and the presence of bifurcated setae of the ' $b$ ' group on the distal segment. Another distinctive character shared by both genders is the relatively short innermost caudal seta, about 2.2 times as long as the ramus; it is as long as that described in the females M. chilensis (see Fig. 4A and SuárezMorales et al., 2006: Fig. 2A), but not as short as in the new species M. igniterra. Furthermore, both sexes cooccurred during the same survey in an area with an 

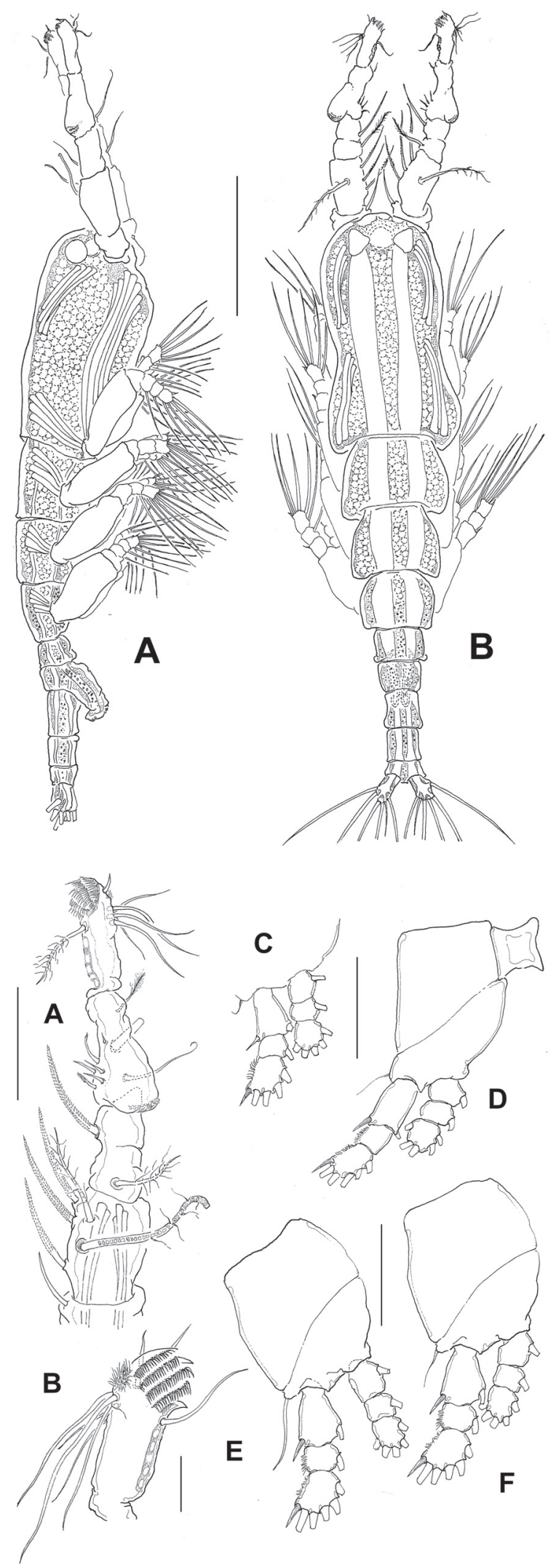
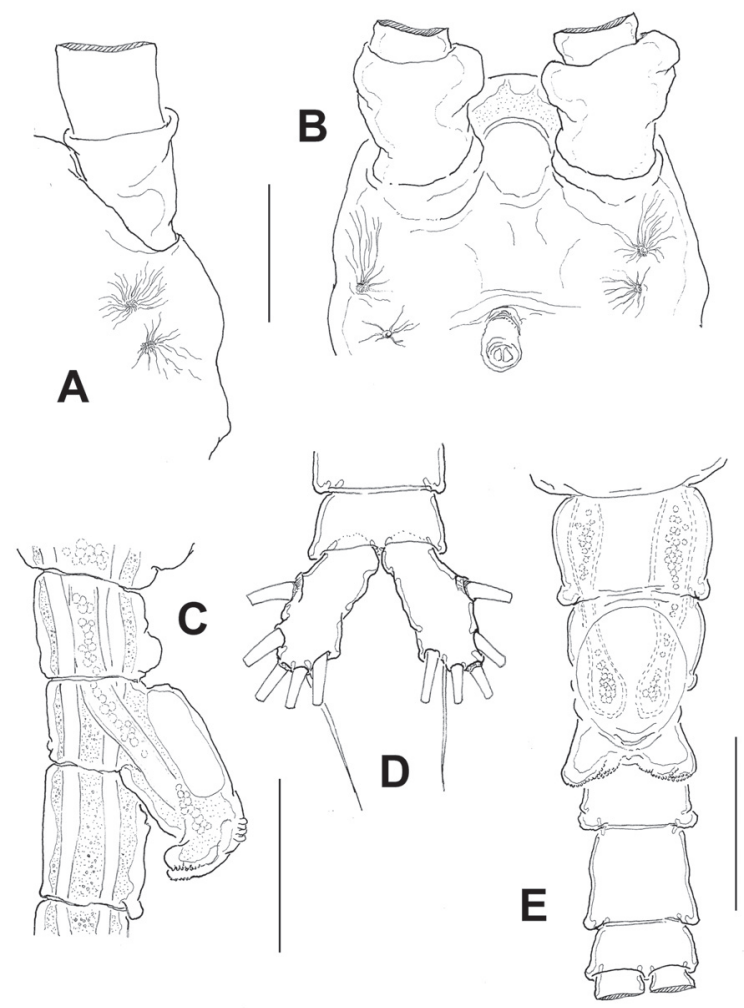

Fig. 5. Monstrilla patagonica n. sp., adult male holotype from Bahia Brown, Beagle Channel.

Left panel: A) habitus lateral; B) habitus dorsal. Scale bars= $300 \mu \mathrm{m}$.

Right panel: A) cephalic area, lateral, showing nipple-like processes and radial wrinkles; B) same, ventral view; C) genital complex, lateral; D) caudal rami, dorsal; E) urosome and genital lappets, ventral. Scale bars $=100 \mu \mathrm{m}$.

Bottom panel: A) right antennule, dorsal; B) details of distal antennular segment; C) first swimming leg; D) second swimming leg; E) third swimming leg with longer basipodal seta; F) fourth swimming leg. Setae of swimming legs 1-4 cut short. Scale bars $=50 \mu \mathrm{m}$ in $\mathrm{B}$ and $100 \mu \mathrm{m}$ otherwise.

impoverished monstrilloid fauna. Hence, based on shared distinctive characters and on co-occurrence, the females of $M$. chilensis are matched with this newly described male. After Monstrillopsis dubioides (see Suárez-Morales and Ivanenko, 2004) and M. zernowi Dolgopolskaya, 1948 (see Dolgopolskaya, 1948), $M$. chilensis is the third species of the genus that is known from both sexes.

Following the revision by Suárez-Morales et al. (2006), the genus Monstrillopsis includes the following nominal taxa: $M$. dubia from Scotland $\left(60^{\circ} \mathrm{N}\right), M$. zernowi from the Black Sea $\left(43^{\circ} \mathrm{N}\right), M$. sarsi from England $\left(54^{\circ} \mathrm{N}\right), M$. fosshageni Suárez-Morales and 
Dias, 2001 from Brazil $\left(20^{\circ} \mathrm{S}\right), M$. dubioides from Norway $\left(62^{\circ} \mathrm{N}\right), M$. ferrarii from the White Sea in the Arctic Ocean $\left(66^{\circ} \mathrm{N}\right)$, M. chilensis from off Chile $\left(33^{\circ} \mathrm{S}\right)$, and $M$. igniterra from the Southern Ocean $\left(55^{\circ} \mathrm{S}\right)$. Only two of the eight species of Monstrillopsis has been recorded from subtropical areas (M. fosshageni and $M$. cf. dubia) (Dias and Bonecker, 2007b). Currently, the distribution of the genus seems to be largely restricted to temperate and cold latitudes. Many records from various geographic areas have been assigned to $M$. dubia. Suárez-Morales and Ivanenko (2004) suggested that records of M. dubia from Europe and North America should be revised; some of these might actually pertain to closely related species of the Northern Hemisphere, such as $M$. ferrarii or $M$. dubioides, whereas those from the Southern Hemisphere could refer to M. chilensis or M. igniterra.

Monstrilla patagonica n.sp.

Material examined. Holotype. Adult male from Bahia Brown, Beagle Channel, collected March, 2006, specimen ethanol-preserved, undissected (ECO-CHZ-03585). Adult male from same area and date, mounted in glycerine, undissected, slide deposited at INIDEP.

Total body length $1.13 \mathrm{~mm}$, measured from anterior end of cephalothorax to posterior end of anal somite (see Fig. 5). Cephalothorax $0.45 \mathrm{~mm}$ long in holotype, representing up to $39.5 \%$ of total body length. Oral papilla not protuberant, located $25 \%$ of way back along ventral surface of cephalothorax. Pair of ocelli present, pigment cups well developed, subtriangular in dorsal view, moderately pigmented in central portion, faint on outside margins. Cephalic region with smooth dorsal surface, and no sensilla observed there. Two pairs of usual nipple-like cuticular processes on anterior ventral surface between antennule bases and oral papilla; processes radially ridged and furrowed. Other ventral cuticular ornamentation including faint transverse wrinkles anterior to oral area, not visible except at high magnification.

Antennule length $0.48 \mathrm{~mm}$ in holotype, equal to $49 \%$ of total body length and about as long as cephalothorax. Antennules fivesegmented, armed with 0-I; 1-V; 2-I; 10-VIII setae (Arabic numerals) and spines (Roman numerals), plus two aesthetascs. Element 1 present on first segment; elements $2 \mathrm{~d}_{1}, 2 \mathrm{v}_{1-3}$, and IId on second segment, element $2 \mathrm{~d}_{2}$ not seen. Third segment with elements 3 and IIId, element IIIv not observed, possibly broken off. Segment four bearing elements $4 \mathrm{~d}_{1,2}$ and $4 \mathrm{v}_{1-3}$ as well as setae IVv, Vv, and $\mathrm{Vm}$. Fifth segment with setal elements 1-7 on anterior margin, posterior margin with unbranched subterminal element D (distalmost), margin with thick-walled cuticular processes. Segment modified, with terminal processes forming several comb-like rows of spinules, with subdistal tuft of hair-like elements.

Cephalically incorporated first pedigerous somite and succeeding three free pedigerous somites each bearing pair of biramous swimming legs. Pedigerous somites 2-4 together accounting for $34 \%$ of total body length in dorsal view. Intercoxal sclerites of legs 1-4 rectangular. Basis with hair-like lateral seta on legs 1-4; on leg 3, this seta about 2.5 times longer and slightly thicker than on other legs. Endopodites and exopodites of swimming legs 1-4 triarticulated, outer margins of exopodites hirsute. Ramus setae all biserially plumose except spiniform outer seta ('spine') on exopod 1 and 3 , and inner seta of first exopodal segment, these latter being short and smooth.

Armature formula of swimming legs are: leg 1- basis 1-0, endopodite $0-1 ; 0-1 ; 1,2,2$ and exopodite I- $1 ; 0-1 ; \mathrm{I}, 2,2$ and legs $2-4$ - basis 1-0, endopodite $0-1 ; 0-1 ; 1,2,2$ and exopodite I-1;0$1 ; \mathrm{I}, 1,2,2$.

Fifth legs absent. Genital complex strongly built, with enlarged base protruding ventrally and subdistal field of transverse cuticular furrows; complex distally branched to form two short, rounded lappets bearing distal rows of blister-like processes.

Urosome consisting of four somites: fifth pedigerous somite, genital somite, two free postgenital somites, and free anal somite. Fifth pedigerous somite representing about $5 \%$ of total body length, with rounded ventral process on distal half, visible in lateral view; postgenital somite largest. Ratio of lengths of urosomites 18.4: 16.2: 30.6: 20.4: $14.2=100$. Furcal rami subrectangular, $0.07 \mathrm{~mm}$ long, moderately divergent, approximately 2 times longer than wide, each bearing six setae: three terminal, one outer, and two on inner margin. One inner seta noticeably shorter and more slender than other setae.

Host. Unknown.

Female. M. helgolandica (sensu Ramírez, 1971) from southern Argentine. See remarks.

Etymology: The new species name makes reference to the Patagonia, the biogeographic province in South America in which this species was collected.

The male specimen was assigned to the genus Monstrilla based on its having a modified antennule with a distal segment armed with several comb-like structures. These structures have been found only in this genus (McAlice, 1985; Huys and Boxshall, 1991). There is a small group of species of Monstrilla with this kind of antennules, which includes $M$. helgolandica, $M$. serricornis Sars, 1921, and M.pygmaea Suárez-Morales, 2000 (McAlice, 1985; Suárez-Morales, 2000). As stated by McAlice (1985), M. canadensis McMurrich, 1917 and not $M$. serricornis is the male of M. helgolandica; hence, the validity of $M$. canadensis is doubtful and it was not separately considered here for comparison.

Several characters present in the new species differ from those in the other known male congeners. For example, the antennules are relatively longer (38\% of total body length) in the new species than in M. helgolandica (31\%) [as depicted by McAlice (1985) based on a syntype specimen], or M. serricornis (30\%; see Sars, 1921, McAlice, 1985), but relatively shorter than in M. pygmaea (41\%; see Suárez-Morales, 2000). The presence of six caudal setae is also an important distinguishing character since males of the other three species of Mon- 
strilla comprising this group have only five (see McAlice, 1985; Suárez-Morales, 2000). The genital complex of the new species is similar to that found in the other species contained in this group, but it displays subtle differences from each of them. In the new species it is slightly stronger and more anteriorly projected than in M. helgolandica and M. serricornis (see McAlice, 1985: Figs. 1,2); it is most similar to that found in M.pygmaea (Suárez-Morales, 2000), but has a coarse corrugation on the distal end of the shaft, which is absent in M.pygmaea . The fourth antennular segment of the new species has a rounded proximal process on the outer margin, which is very pronounced, bulging laterally in dorsal view and with blister-like cuticular ornamentations on its proximal surface; in M. serricornis this process is smooth and clearly weaker than in M. patagonica n.sp. (McAlice, 1985: Fig. 1). In M. helgolandica these processes are absent (McAlice, 1985: Fig. 2).

There is a record of a female of $M$. helgolandica (Ramírez, 1971) from the Patagonian region off Argentina $\left(46^{\circ} \mathrm{S}\right)$; this ovigerous female specimen was carefully described and illustrated. It shows several important characters that diverge from $M$. helgolandica (sensu McAlice, 1985), including a slender cephalothorax with a wide forehead ( $v s$. a robust cephalothorax and narrow forehead in $M$. helgolandica), a relatively longer antennule (26\% of total body length vs $13.2 \%$ in M. helgolandica), longer ovigerous spines (reaching well beyond the distal margin of the caudal rami in the Argentinian specimens, vs. spines barely reaching the posterior margin of the caudal rami) (see McAlice, 1985: Fig. 2B), noticeably more slender and longer fifth legs, and diverging caudal rami. The genital double somite is relatively longer in the Argentinian specimens, 1.75 times as long as the two succeeding somites combined, whereas it is only about as long as these somites in $M$. helgolandica (see McAlice, 1985). A female specimen from the adjacent Ushuaia Bay, collected by Biancalana et al. (2007) was examined and these differences were confirmed. In light of (1) the general morphological resemblance of the male of M.patagonica $\mathrm{n}$. sp. to $M$. helgolandica, with the presence of pectinate antennules and the same type of genital lappets, (2) the differences from $M$. helgolandica in both sexes from Argentinian waters, (3) the close resemblance of females and males of $M$. helgolandica with other species (see Grygier and Ohtsuka, 1995), (4) the fact that only one such species has been recorded from the southern shores of Argentina, and (5) this being the only record of of Monstrilla males with pectinate antennules from the southern hemisphere, it is clear to us that the specimen depicted from this area more than 35 years ago (Ramírez, 1971) is the female of M.patagonica n. sp. Further, this species seems to be distributed in other coastal systems along the Beagle Channel, including Ushuaia Bay (Biancalana et al., 2007). In Bahia Blanca, Argentina, at the same general latitude range $\left(42^{\circ} \mathrm{S}\right)$, records include Monstrilla sp., M. helgolandica, and M. aff. serricornis (Hoffmeyer and Barría de Cao, 2007). It is not explicitly stated if the latter records are from females or males, but it is probable that the females were identified as M. helgolandica following Ramírez (1971) and the males as $M$. aff. serricornis based on the characteristic pectinate antennules. These records could be tentatively assigned as representing $M$. patagonica.

Species of Monstrilla with pectinate antennules in the male have been known to occur mainly from the northern hemisphere, including Maine and Alaska, in the United States, Canada, northern France, England, and Norway, but also from tropical areas (Gilbert Islands, Mindanao, and North Africa) (McAlice and Jaeger, 1982; McAlice, 1985). Monstrilla pygmaea is known only from the Mediterranean (Suárez-Morales, 2000). This is the first record of males of this group from the southern hemisphere.

\section{Acknowledgements}

Mónica Hoffmeyer, Instituto Argentino de Oceanografía (CONICET- UNS) kindly allowed us to examine material of Monstrilloida from the Beagle Channel. We express our gratitude to Gastón Aguirre, Universidad de Buenos Aires for his support and encouragement to develop this work. This work was supported by projects PIP5009 and IAI-CRN2076 granted to two of us (FR and CD). Rosa Ma. Hernández (El Colegio de la Frontera Sur at Chetumal), accepted the type specimens for deposition in the Zooplankton Collection there and provided their catalogue numbers.

\section{References}

Bradford-Grieve J, Markhaseva E, Rocha CE, Abiahy B. 1999. Copepoda. In: Boltovskoy D, ed. South Atlantic Zooplankton. Leiden: Backhuys, 869-1098.

Biancalana F, Barría de Cao MS, Hoffmeyer MS. 2007. Micro and mesozooplankton composition during winter in Ushuaia and Golondrina bays (Beagle Channel, Argentina). Brazilian Journal of Oceanography 55: 83-95.

Bujalesky G, Aliotta S, Isla F. 2004. Facies del subfondo del canal Beagle, Tierra del Fuego. Revista de la Asociación Geológica de Argentina, Buenos Aires 59: 29-37.

Davis CC, Green JM. 1974. Three monstrilloids (Copepoda: Monstrilloida) from the Arctic. Internationale Revue der Gesamten Hydrobiologie 59: 57-63.

Dias CO. 2005. Taxonomy and geographic distribution of the Monstrilloida (Copepoda Crustacea) from the South Occidental Atlantic. Biota Neotropica 5: 1-2. 
Dias CO, Bonecker SL. 2007a. New records of Monstrilloida Sars, 1901 (Crustacea, Copepoda) on the Brazilian northeastern coast. Biota Neotropica 7: 1-5.

Dias CO, Bonecker SL. 2007b. Study of Monstrilloida distribution (Crustacea, Copepoda) in the Southwest Atlantic. PanAmerican Journal of Aquatic Sciences 2: 270-278.

Dolgopolskaya MA. 1948. K faune Monstrillidae Chernogo morya. Trudy Zoologicheskogo Instituta Akademii Nauk SSSR 7: 177-183. (in Russian)

Fernández-Severini MD, Hoffmeyer M. 2005. Mesozooplankton assemblages in two bays in the Beagle Channel (Argentina) during January 2001. Scientia Marina 69 (Suppl. 2): 2737.

Gallien L. 1934. Description du mâle de Monstrilla helgolandica Claus. Synonymie de Monstrilla serricornis G.O. Sars et de Monstrilla helgolandica Claus. Bulletin de la Société Zoologique de France 59: 377-382.

Grygier MJ. 1994. Identity of Thaumatoessa (=Thaumaleus) typica Krøyer, the first described monstrilloid copepod. Sarsia 78: 235-242.

Grygier MJ, Ohtsuka S. 1995. SEM observation of the nauplius of Monstrilla hamatapex, new species, from Japan and an example of upgraded descriptive standards for monstrilloid copepods. Journal of Crustacean Biology 15: 703-719.

Grygier MJ, Ohtsuka S. 2008. A new genus of monstrilloid copepods (Crustacea) with anteriorly pointing ovigerous spines and related adaptations for subthoracic brooding. Zoological Journal of the Linnean Society 152: 459-506.

Ho J-s, Dojiri M, Hendler G, Deets GB. 2003. A new species of Copepoda (Thaumatopsyllidae) symbiotic with a brittle star from California, U.S.A., and designation of a new Order Thaumatopsylloida. Journal of Crustacean Biology 23: 582-594.

Hoffmeyer MS, Barría de Cao MS. 2007. Zooplankton assemblages from a tidal channel in the Bahía Blanca Estuary, Argentina. Brazilian Journal of Oceanography 55: 97-107.

Huys R, Boxshall GA. 1991. Copepod Evolution. London: The Ray Society, London, 468.

Huys R, Llewellyn-Hughes J, Conroy-Dalton S, Olson PD, Spinks JN, Johnston DA. 2007. Extraordinary host switching in siphonostomatoid copepods and the demise of the Monstrilloida: Integrating molecular data, ontogeny and antennulary morphology. Molecular Phylogeny and Evolution 43: 368-378.

Isaac MJ. 1974. Copepoda Monstrilloida from south-west Britain including six new species. Journal of the Marine Biological Association of the United Kingdom 54: 127-140.

Marín V, Antezana T. 1985. Species composition and relative abundance of copepods in Chilean fjords. Journal of Plankton Research 7: 961-966.

McAlice BJ. 1985. On the male of Monstrilla helgolandica Claus (Copepoda, Monstrilloida) Journal of Crustacean Biology 5: 627-634.

McAlice BJ, Jaeger GB. 1982. Seasonality of Monstrilla helogolandica Claus, 1863 (Copepoda, Monstrilloida) and the occurrence of other monstrilloids in Maine. Journal of Crustacean Biology 2: 45-47.

Ramirez FC. 1971. Nuevas localidades para Monstrilla grandis Giesbrecht 1892 y Monstrilla helgolandica Claus 1863 (Copepoda, Monstrilloida) hallados en aguas de la plataforma Argentina. Physis, Buenos Aires, 30: 377-383.

Razouls C. 1996. Diversité et répartition géographique chez les copépodes pélagiques. 2.- Platycopioida, Misophrioida, Mormonilloida, Cyclopoida, Poecilostomatoida, Siphonostomatoida, Harpacticoida, Monstrilloida. Annales de l' Institut Océanographique Nouvelle Série 72: 1-149.

Sars GO. 1921. An account of the Crustacea of Norway with short descriptions and figures of all the species. Vol. VIII. Copepoda Monstrilloida and Notodelphyoida. Bergen: The Bergen Museum, 91.

Scott T. 1904. Notes on some rare and interesting marine Crustacea. Twenty-second Annual Report of the Fishery Board for Scotland, being for the Year 1903. Part III. Scientific Investigations. 242-260, pls. XIII-XV.

Suárez-Morales E. 2000. Taxonomic report on some monstrilloids (Copepoda, Monstrilloida) from Toulon Bay, France. Bulletin de l'Institut Royal des Sciences Naturelles de Belgique, Biologie 70: 107-118.

Suárez-Morales E. 2001. An aggregation of monstrilloid copepods in a western Caribbean reef area: ecological and conceptual implications. Crustaceana 74: 689-696.

Suárez-Morales E. 2005. Validation and redescription of Cymbasoma germanicum (Timm) (Crustacea: Copepoda: Monstrilloida) from Helgoland with comments on C. rigidum Thompson. Helgoland Marine Research 60: 171-179.

Suárez-Morales E, Dias C. 2001. Taxonomic report of some monstrilloids (Copepoda: Monstrilloida) from Brazil with description of four new species. Bulletin de l'Institut Royal des Sciences Naturelles de Belgique. Biologie 71: 65-81.

Suárez-Morales E, Escamilla JB. 1997. An undescribed monstrilloid copepod (Copepoda: Monstrilloida) from the northern Yucatan Peninsula, Mexico. Bulletin of Marine Science 61: 539-548.

Suárez-Morales E, Gasca R. 2004. On the invalidity of Strillo$m a$ Isaac (Copepoda: Monstrilloida): observations from the type species. Zoological Studies 43: 292-299.

Suárez-Morales E, Ivanenko VN. 2004. Two new species of Monstrillopsis Sars (Crustacea: Copepoda: Monstrilloida) from the White Sea and Norway, with comments on $M$. dubia Scott. Arctic 57: 37-46.

Suárez-Morales E, Bello-Smith A, Palma S. 2006. A revision of the genus Monstrillopsis Sars (Crustacea: Copepoda) with description of a new species from Chile. Zoologischer Anzeiger 245: 95-107.

Received: 19 March 2008

Accepted: 25 September 2008

Published online: 22 December 2008 